\title{
Application of double skin in the ecological architecture design of Thomas Herzog
}

\author{
Shengnan $\mathrm{Niu}^{1}$, Li Yang ${ }^{2}$ \\ ${ }^{1}$ School of Civil engineering, Shandong University, \\ ${ }^{2}$ College of Architecture \& Urban Planning, Tongji University,
}

\begin{abstract}
The purpose of this research is to investigate the use of double skin in Thomas Herzog's works. Double skin is an important method of green building design, and it is also one of the building energysaving techniques that Thomas Herzog often uses. This paper discusses some of the common features of Herzog's application of double skin by summarizing some of Herzog's works and comparing them with the actual construction of Chinese ecological buildings.
\end{abstract}

\section{Two scales of double-skin energy saving}

Thomas Herzog is a world-renowned German master of ecological architecture design. He always adheres to the principle of "from ecology to architecture, from technology to nature". As a passive way to use solar energy at present, double skin has special application characteristics in Herzog's architectural works. In the ordinary sense, the energy saving of double-skin facade mainly refers to the situation when the scale of air interlayer between skins is small. But when the scale of the air interlayer is too large and it has certain use value, it is generally called solar house. Herzog has added both scales of double skin energy-saving techniques into his architectural works, which also achieved good results in building energy efficiency.

\section{Herzog's double skin application}

Double skin is often found in Herzog's works because of its simple structure, strong regulation, and easy combination with other techniques. Some scholars commented on Herzog's architectural works: "It is not the structure that plays the main role, but the dynamic and changing skin, which connects with specific places and responds to the changing environment." In the case of Two-Family House, there are prefabricated concrete slabs with good thermal storage capacity inside the facade glass, which belong to Trombe Wall structure and have a good regulating effect on the indoor thermal environment. Different from Two-Family House, TIM wall is used in Guest Building for the Youth Education Centre. However, in the building of DMAG in Hanover, the double-deck elevation is enlarged and the structural pillars are set in the double-deck glass sandwich (Fig.1), which not only make the elevation unaffected by the pillars, but also make it easier to clean. There is also a variant form of double skin, namely double roof, which is often found in Herzog's works. For example, doubledeck roof is used in Regensburg House and Munich Housing Development. In these cases, the triangular section of double-deck roof is conducive to organizing natural ventilation, and the air layer in the middle forms a thermal buffer layer, which is conducive to thermal insulation. In addition, the best way to embody the double-decked roof is a warehouse renovation (Fig.2). The building was originally a warehouse, and the owner hopes to transform this building into a design studio. In order to minimize the cost, the main body of the building has hardly been changed. The facades and roof are all keep the condition of the original warehouse. However, the thermal condition of the building must be improved to meet the internal functional requirements. Faced with this problem, Herzog uses a double-layer membrane structure, with a layer of membrane at the lower part of the roof. The air layer inside the roof plays a role of thermal insulation and thermal buffering, and forms a double-layer roof with the original roof. At the same time, the thermal insulation also makes the internal section shape triangle, which is conducive to the organization of indoor natural ventilation.

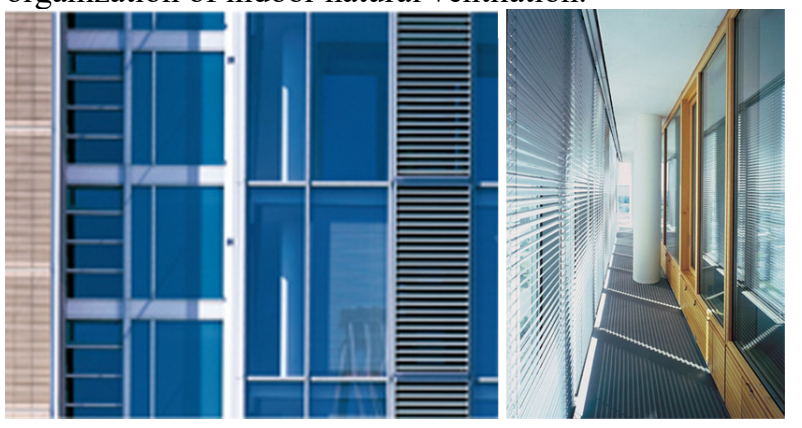

Fig.1. Double skin in DMAG

\footnotetext{
* Corresponding author: yangli.arch@tongji.edu.cn
} 


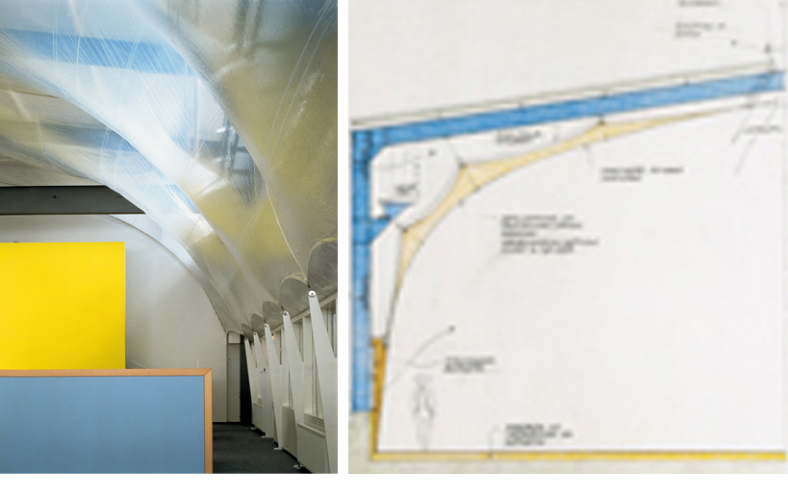

Fig.2. Double-decked roof in a warehouse renovation

\section{Herzog's Solar House Application}

\subsection{Section of triangle}

It is one of Herzog's usual ways to make a triangular section of a building. The purpose of this method is that the triangular section can maximize the solar energy indoor comparing with the square section. With the use of glass skin, the building itself can become a solar house, equivalent to the direct benefit of the solar house. Moreover, the triangular roof will have a certain slope, which is not only conducive to drainage, but also can directly lay solar panels to provide clean energy for buildings. In many works such as Regensburg house, Munich Housing Development, Linz Design Centre and Hannover Hall, the main sections of the building are designed as triangles.(Fig.3)The sections of Regensburg House and Munich House are right triangle and the inclined roof maximizes the sunlight entering the room. What is more, the indoor floor uses heat storage materials, which can store heat at daylight and release heat at night to maintain the indoor heat balance. Relatively, in Linz design centre, Summer Villa and New Production Plant For the Deutsche Werkstatten, the sections of these buildings are designed as an isosceles triangle. (Fig.4) The two roof slopes of these buildings can not only transmit a lot of sunlight, but also facilitate the installation of solar panels. In addition, the indoor triangular section is also conducive to the organization of indoor ventilation.

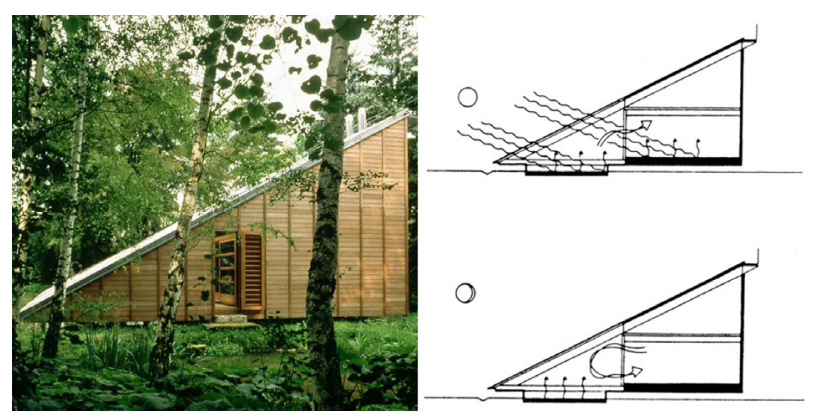

Fig.3. Right triangle section

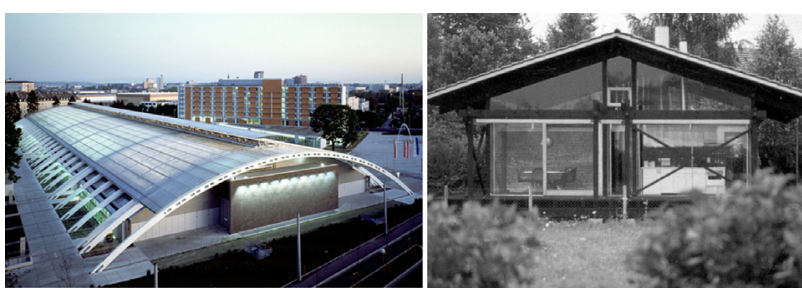

Fig.4. Isosceles triangle section

\subsection{Rectangular plan}

In order to maximize the sunshine in the building, $\mathrm{Mr}$. Herzog often turns the graphic design into a rectangle, whose depth is usually small, but the width is large. (Fig.5)Generally, the south-facing rooms need sunshine, while the north-facing rooms need some auxiliary rooms. In the setting of the outer facade, the south facade is usually made of large pieces of glass in order to maximize the absorption of sunlight. But in order to prevent overheating in summer, some shading measures will also be set on the south facade. What is more, solid walls are usually used in the north to prevent heat loss. All of these design methods can be clearly seen from the plan of the buildings such as Regensburg house, Munich Housing Development, Two-family house and Guest building for the Youth Education Centre. Similarly, all the plans in these cases, their depth is much shorter than the width, which may facilitate the natural ventilation within the organization. Almost all the south-facing facades are made of large transparent glass to maximize the use of solar energy, while the north-facing facades are much thicker. In addition, all the interior longitudinal walls are movable, so that the owners of the house can arrange the interior space according to their own needs, providing great flexibility.
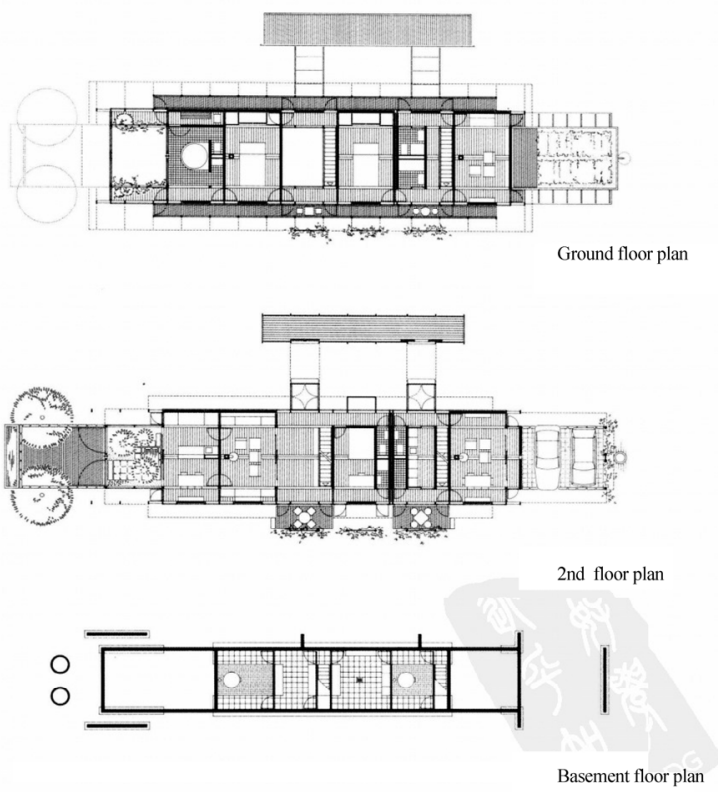

Fig.5. Rectangular plan in Two-Family House 


\subsection{Special position of greenhouse}

Herzog often sets greenhouses in buildings in some special locations or combines greenhouses with other functions, so that to maximize the utilization of resources and functions. Besides, such layout can be used in combination with several techniques of the solar house.

\subsubsection{High solar house}

In Two-Family House and Guest building for the Youth Education Centre, both of these buildings have set up a high solar house space. (Fig.6)Its purpose is to fully accept the use of solar energy, while simultaneously bringing greenhouse effect into double-deck space. Double-decked solar houses can also be used as greenhouses for growing higher plants and the principle of this design is independent benefit solar house.

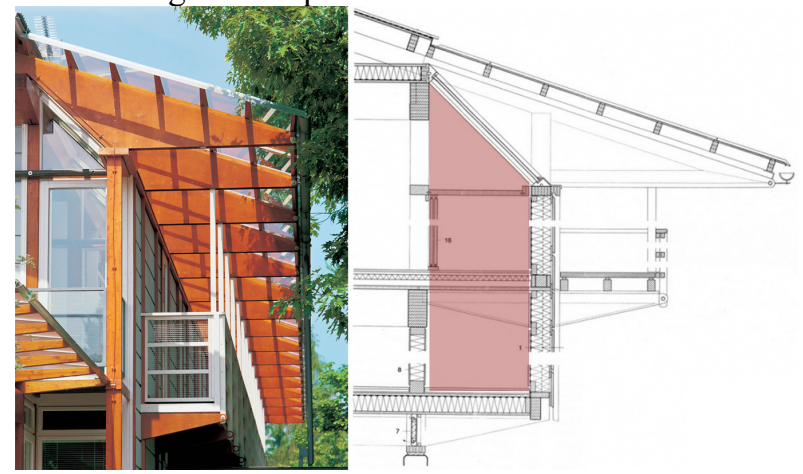

Fig. 6. High solar house in Two-Family House

\subsubsection{The solar house pulling out the roof}

Practically, the application of solar house is introducing sunlight into the interior, but sometimes the angle of sunlight is not suitable for building use. There are various ways to solve this problem. However, Herzog chooses the most direct one, which is pulling the solar house out of the roof, so that the pulled out part can receive sunlight directly. It belongs to the independent beneficiary method. What is more, Herzog also makes full use of this method in other cases, such as Courtyard Housing for the Federal German Gardens Exhibition, Solar city and Holzstrasss Housing Development. However, these pulled-out solar houses, while receiving sunlight, also give other uses. In Courtyard, the solar house is actually the inner courtyard of the building. While providing greenhouse function, it strengthens the indoor ventilation and lighting.(Fig.7) While in Production Halls, the auxiliary space in the workshop is put out to form a greenhouse. In Solar city, the roof of traffic space is put out to form a greenhouse, which can not only provide heat for the surrounding rooms in winter, but also strengthen the communication between neighbours.

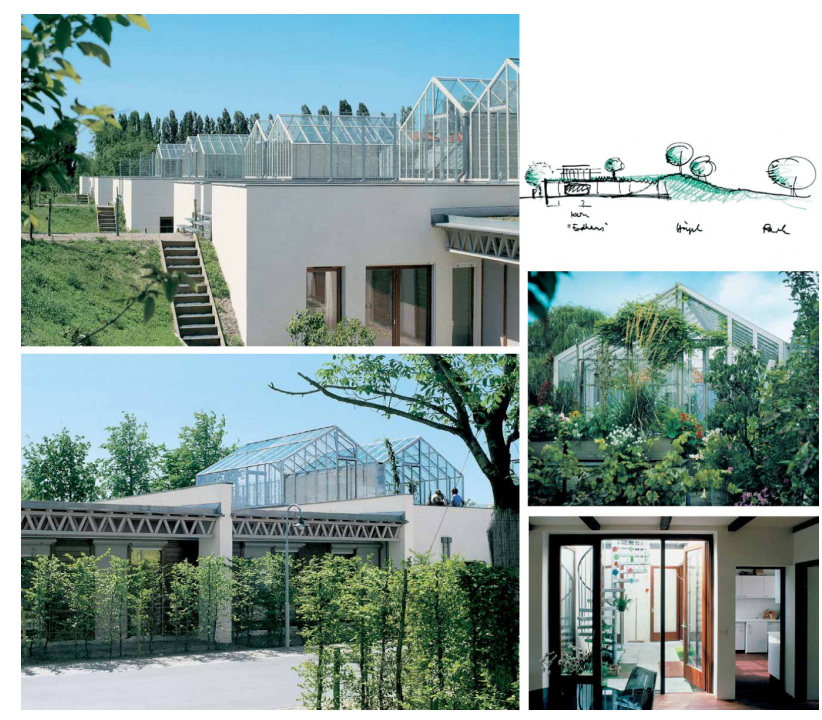

Fig.7. The solar house pulling out the roof in Courtyard Housing for the Federal German Gardens Exhibition

\subsubsection{Solar house corridor}

Among Herzog's works, the most common use of the solar house is the use of the solar house as a corridor, which could be seen in the Two-Family, Doctor's House and Conference and Exhibition Building for the German Federal Environmental Foundation. (Fig.8) The south facade of the corridor house is made up of large pieces of glass, and the interior room uses the corridor as a shade. In the winter daytime, the interior wall of the corridor absorbs sunlight. While at night, it can release heat to the interior and adjust the indoor thermal environment.Therefore, this kind of solar house belongs to the type of independent beneficiary solar house. In the design of Two-Family, the corridor on the second floor provides sunshade for the first floor, and the corridor and the sloping roof form a greenhouse together. While in Doctor's House, the front corridor serves as a vehicle connecting rooms, an art exhibition hall and a greenhouse in winter.
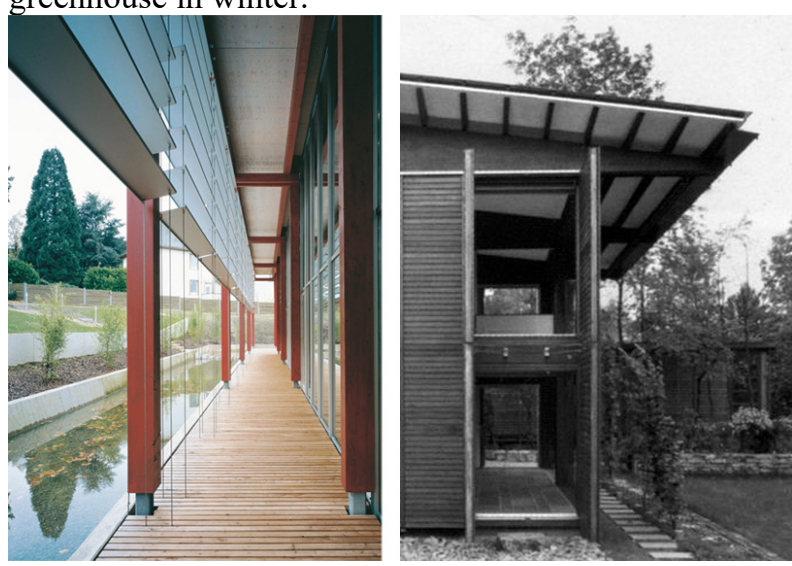

Fig.8. Solar house corridor in Conference and Exhibition Building and Doctor's House 


\section{Development and application prospect of energy conservation in double skin buildings in China}

The energy-saving concept of double-skin building is also of great significance to China, and it plays an immeasurable role in alleviating the natural environment. Herzog's design provides us with a variety of double skin energy-saving ways, and many of which can be used for reference in different regions of China. First of all, the use of double skin is common in urban public buildings, generally used in high-rise office buildings. With the change of internal cavity scale, the use function of internal space also changes. While the triangle section principle is more suitable for rural residential in China, because of the limitation of internal space, which is not suitable for use in high-density cities. The rectangular plane can be used for residential buildings in some hot summer and warm winter areas. Because these areas need to strengthen ventilation and dehumidification, and the rectangular plane is the most suitable one. As for the special usage of greenhouse, the pulled-out solar house is usually used in areas with high solar altitude and short sunshine time, which can make full use of solar energy. At the same time, the patio and courtyard in the north and South can be covered with glass roof to form a sunshine room space. In a word, Herzog's double-skin energy-saving concept not only has unique advantages, but also has great adaptability. It can also be flexibly adopted in our country. It can not only be used for new buildings but also for the transformation of old buildings. It has great reference significance for us.

\section{Conclusion}

Thomas Herzog is a top expert in building technology, who has a wide variety of techniques for handling architecture. However, after the above analysis, we can see that Herzog's technique is actually the most direct method. If the building needs sunlight, then he tilts the roof to the maximum. If it is not enough, he would choose to pull out the roof. And such construction techniques are often used in Herzog's work. In recent decades, we are too eager to pursue the complicated and varied construction techniques, but forget the most original comfort of the building. However, when we look back at Herzog's work, we may realize that perhaps the simplest and most direct language is the best.

\section{References}

1. Master of Architecture Series Editorial Department, Thomas Herzog's architectural works and thoughts (China Electric Power Press, 2006)

2. Hua. Ri, World architecture, 2 (1999).

3. Yi.Hou, Decoration,6 (2008).

4. Flagge Ingeborg, Thomas Herzog (Architecture + Technology) (China Architecture \& Building Press, 2003)
5. Nik Eteghad. A, Uson Guardiola. E, Hosseini Raviz. SR, Armesto Aira. A, Architecture City And Environment, 7,27 (2015) 